\title{
Hacia una perspectiva interdisciplinaria
}

El diálogo interdisciplinario es un imperativo en la actualidad. Una visión segmentada de la realidad, en monólogo con los instrumentos y discursos de una disciplina determinada resulta insuficiente y - qué duda cabe-hasta ideologizadora. Es ideologizadora, por cuanto una visión de la realidad que no establece conexiones entre las distintas áreas del conocimiento, haciendo ver situaciones negativas para la vida humana como "espontáneas", "naturales" y hasta "lógicas", cuando en realidad no lo son.

Es necesaria una interdisciplinariedad, entendida no como una mera yuxtaposición de datos procedentes de campos científicos particulares, sino como una aproximación hacia una visión compleja y dinámica de la realidad histórica. La interdisciplinariedad no significa la "colonización" de las especificidades de una disciplina en nombre de otra. El que una disciplina determinada dialogue con otra, no significa que los rasgos distintivos de la disciplina A se desdibujen al grado de mimetizarse con la disciplina B. Así, por ejemplo, la filosofía, aunque dialogue con la psicología, la historia o la sociología, debe conservar su talante propio y no convertirse en una mala psicología, una mala historia o una mala sociología. Mala, en el sentido de que carece del instrumental teórico adecuado para dar cuenta de cada área del conocimiento. El razonamiento en sentido inverso también es válido. Ahora bien, de lo que se trata es que, sin perder la especificidad de cada disciplina, se pueda tener un conocimiento complejo de los fenómenos. La interdisciplinariedad se convierte, así, en una forma de desideologización, en una crítica de la visión fragmentada de la realidad. 
En este número se pone a la disposición del público investigaciones recientes sobre temas como la educación, los procesos de laicización o la construcción de subjetividades de mujeres, indígenas y migrantes. Estos temas son analizados de tal manera que la clásica investigación histórica se nutre del diálogo con los estudios culturales, la filosofía, la literatura, el derecho y otras perspectivas analíticas y metodológicas.

El presente número recoge, pues, una serie de ensayos que tienen en común el análisis histórico de distintos fenómenos culturales, sociopolíticos y jurídicos de El Salvador entre los siglos XIX y XX. Algunos de ellos son resultado de las investigaciones realizadas por sus autores para optar al grado de Doctor en Filosofía Iberoamericana. Tal es el caso de los trabajos elaborados por Olga Vásquez, Roberto Valdés y Julián González. Muy sugerentes resultan también los trabajos de los investigadores Ricardo Roque Baldovinos y de Moisés Gómez, que enfocan con nuevos ojos la construcción literaria de "lo indígena" o los fenómenos migratorios. 